\title{
INVESTMENT OF THE UNIFIED HEALTH SYSTEM IN SCREENING MAMMOGRAPHY IN BRAZIL, 2008-2017
}

Danielle Cristina Netto Rodrigues', Ruffo Freitas-Junior¹, Rosemar Macedo Sousa Rahal'1, Luiz Paulo da Silveira Corrêa ${ }^{1}$, Rosangela da Silveira Corrêa ${ }^{1}$

${ }^{1}$ Centro Avançado de Diagnóstico da Mama, Universidade Federal de Goiás, Rede Brasileira de Pesquisa em Mastologia Goiânia (GO), Brazil.

Objective: To evaluate the investment of financial resources applied by the Unified Health System (SUS), in the mammographic screening performed by in Brazil, from 2008 to 2017. Methods: A prospective study where the number of mammograms performed by the SUS was observed in women aged 50-69 years and the value approved for payment of the respective examinations, available in the Outpatient Information System (SIA/DATASUS). The amount approved for payment was compared with the amount established for the SUS (R\$ 45.00) and the number of exams performed. Results: In the period evaluated, $\mathrm{R} \$ 968,567,514.42$ were invested in mammographic screening by the Union, for a total of 22,214,981 examinations performed, at a unit value of $\mathrm{R} \$ 43.60$. When comparing this value with that established by the SUS (R $\$ 45.00)$, it is possible to infer a surplus for the System of $\mathrm{R} \$ 31,106,630.58$, which would represent the accomplishment of approximately 691 thousand new exams. On the other hand, the amount paid per examination remained fixed in the 10 years evaluated in the study. In a simple analysis of monetary restatement in relation to inflation in the period evaluated, when applying the Extended Consumer Price Index (IPCA), the expected value for payment of the exam in 2017 would be approximately R $\$ 79.41$. Conclusion: The scenario evaluated suggests that there were resources for the mammographic screening, but not enough to increase the coverage of the exams and maintain the established value for the SUS, of R\$45.00. 